\title{
Spinal anaesthesia in elderly for laparoscopic cholecystectomy
}

\section{Gautam B}

Binod Gautam, Assistant Professor, Department of Anaesthesiology and Intensive Care, Kathmandu Medical CollegePublic Limited

\begin{abstract}
Background: Prevalence of aging patients appearing for laparoscopic cholecystectomy to treat cholelithiasis is ever on the rise. Associated co-morbidities make the elderly prone to peri-operative complications during laparoscopic cholecystectomy performed under general anaesthesia.

Objectives: This study aims to assess the safety and applicability of spinal anaesthesia for the elderly undergoing laparoscopic cholecystectomy.

Methodology: In this cross-sectional study, fifty-four patients of age 65 years or more undergoing laparoscopic cholecystectomy were studied. Hyperbaric Bupivacaine 15 milligrams was used in spinal anaesthesia to obtain sensory block to fifth thoracic dermatome. Local anaesthetics were instilled intra-peritoneally before surgical dissection. Surgery was performed through three ports with carbon dioxide pneumoperitoneum at eight $\mathrm{mmHg}$ intra-abdominal pressure. Data included demography, co-morbidities, need for analgesics or general anaesthesia, operative and post-operative complications and hospital stay. Univariate analysis for peri-operative events and bivariate analysis for outcome and explanatory variables were done.

Results: The mean age was 71.4 years with co-morbidity in 40 patients. Conversion to open cholecystectomy occurred in three patients necessitating general anaesthesia. Surgery was completed laparoscopically under spinal anaesthesia in remaining 51 patients. Increment in intra-abdominal pressure was required in five patients. Six patients needed analgesics for shoulder pain. Intra-operative hypotension and shivering occurred in 15 and four patients respectively. Post-operatively, urinary retention and nausea occurred in four and three patients respectively. Mean hospital stay was 3.2 days.

Conclusion: There is no undue risk in spinal anaesthesia for conducting laparoscopic cholecystectomy in the elderly and it is efficient for uncomplicated cholelithiasis with minimal modifications in surgical technique.
\end{abstract}

Key words: Elderly, General anaesthesia, Laparoscopic cholecystectomy, Spinal anaesthesia.

\section{INIRODUCTION}

$\Lambda$ dvancing age bears direct relations with incidence - of cholelithiasis and its acute complications. Laparoscopic cholecystectomy (LC) is the method of choice for treating cholelithiasis since it enhances recovery ${ }^{1}$. However, considerable peri-operative complications might be witnessed, especially in elderly who have limited physiologic reserves.

General anaesthesia (GA) is the gold standard anaesthetic option for LC. But, requirements for multiple

Address for correspondence

Dr. Binod Gautam

Assistant Professor

Department of Anaesthesiology and Intensive Care, Kathmandu

Medical College Public Limited, Sinamangal, Kathmandu, Nepal.

E-mail: gautambinod@hotmail.com systemic medications and mechanical ventilation might make elderly population high risk candidates for surgery. Elderly after anaesthesia are also prone to deterioration in cognitive functions $s^{2,3}$. Regional anaesthesia is a convincing alternative for patients considered poor candidates for GA, since it offers several advantages including improved immediate post-operative pain-relief and minimal effect on mental status. Spinal anaesthesia (SA) has been safely applied in both healthy and high-risk patients undergoing $\mathrm{LC}^{4-7}$. It avoids the neuro-endocrine stress response associated with laryngoscopy-intubation, mechanical ventilation, surgery and extubation. Reduction in rates of incidence of thrombo-embolic complications, peri-operative cardiac ischemic events, post-operative hypoxic episodes and respiratory complications have been associated with the overall reduction in the incidence of morbidity and 
mortality with the use of SA in sick and elderly patients ${ }^{8}$.

Concerns remain about the safety of SA in the elderly undergoing LC since this application is sparingly available in literature. This prospective study was undertaken to evaluate safety and applicability of SA in the elderly undergoing $\mathrm{LC}$.

\section{METHODOLOGY}

This was a cross-sectional descriptive study done at an operating room, post-anaesthesia care unit and surgical ward in a medical college from January 2014 to December 2016. All the principles outlined in the Helsinki Declaration of 1975, as revised in 2000 have been followed in all the experiments involving human subjects during the current study9. Informed written consent from each 54 participants was obtained during pre-anaesthetic checkup done a day prior to surgery. Participants were fasted for six hours for solid food and two hours for clear liquid. Premedication included Ranitidine $150 \mathrm{mg}$ and Metoclopramide $10 \mathrm{mg}$ on the night before and on the morning of surgery via oral route. Regular medications were not withheld.

Adults of age 65 years or above, from both gender who could communicate well in Nepalese language and scheduled to undergo laparoscopic cholecystectomy for cholelithiasis were included. Patients with the conditions complicating or contraindicating for SA like infectious focus at back, height $<150 \mathrm{~cm}$, previous spine surgery, moderate to severe aortic and mitral stenosis or intake of anticoagulants were excluded. Following surgical conditions were also considered for exclusion criteria; acute cholecystitis, acute cholangitis, acute pancreatitis, suspected malignancies, previous abdominal surgery and surgeons' unwillingness.

Convenience sampling of patients scheduled for LC, belonging to the investigator's operating list were included. They were interviewed and specifically explained about possible events during surgery including anxiety, right shoulder tip pain, abdominal/ respiratory discomfort, shivering, and nausea/vomiting and their respective management options. As there would be multiple outcomes possible, no analysis was undertaken to determine the size of the study group.

In the operating room baseline systolic blood pressure $(\mathrm{SBP})$, heart rate (HR), respiratory rate (RR), and oxygen saturation $\left(\mathrm{SPO}_{2}\right)$ were recorded while routine monitors (non-invasive blood pressure, pulse-oximetry, and electrocardiography) were being established. Peripheral line was secured with an $18 \mathrm{G}$ intravenous cannula and a bolus of $10 \mathrm{ml} / \mathrm{kg}$ Ringer's Lactate solution was infused except in diabetic patients who received Normal Saline $0.9 \%$. Paracetamol one gram, Ondansetron six $\mathrm{mg}$, Dexamethasone six mg except in diabetic patients, and antibiotics were administered. Oxygen was supplemented at four litres/min via Hudson's face mask. Fluid infusion was restricted at seven to $10 \mathrm{ml} / \mathrm{kg} / \mathrm{hour}$ peri-operatively.

Lumbar puncture was performed in a sitting patient under aseptic conditions at L3-L4 or L4-L5 intervertebral space. A $27 \mathrm{G}$ pencil-point spinal needle was passed through a $20 \mathrm{G}$ introducer needle through midline after infiltrating the overlying skin with two $\mathrm{ml}$ of $2 \%$ Lignocaine. Three $\mathrm{ml}$ hyperbaric Bupivacaine $0.5 \%$ (Bupican $^{\text {TM }}$ Heavy: Claris Injectables Ltd, Ahmedabad, India) was injected into sub-arachnoid space over 30 seconds after confirming cerebrospinal fluid aspiration. Patients were made to lay supine immediately in a flat operating table. Level of sensory block was assessed with spirited cotton swabs for loss of sensation to cold till attaining fifth thoracic dermatome (T5) level to allow for surgical proceedings. Failure to attain a bilateral T 5 sensory block within 20 minutes was defined as a block failure and GA was considered in these patients.

Surgery was performed using three-trocar and openlaparoscopy technique. After creating the epigastric port, surgeons instilled $20 \mathrm{ml}$ Bupivacaine $0.25 \%$ on to the diaphragmatic surface of liver under direct visualization. Another $10 \mathrm{ml}$ of similar solution was used to bath the gall bladder and the Callot's triangle. Insufflation flow rate of carbon dioxide $\left(\mathrm{CO}_{2}\right)$ for creating pneumoperitoneum was kept at one litre/min. Table tilt was allowed as much as 15 degrees for both left lateral and reverse Trendelenburg position. Intra-abdominal pressure (IAP) limit was kept at eight $\mathrm{mmHg}$ and increased sequentially to 10 and $12 \mathrm{mmHg}$ only when needed and recorded. Nasogastric tube was not inserted routinely and done if needed, but only after optimizing the table tilts and IAP. Duration of pneumoperitoneum, operative time, creation of fourth surgical port, and insertion of sub-hepatic drain were also recorded.

$\mathrm{HR}, \mathrm{SBP}, \mathrm{RR}$ and $\mathrm{SPO}_{2}$ were monitored continuously and recorded every five minutes throughout the operating period, every 30 minutes for the next four hours and according to the nursing protocol thereafter. Hypoxemia was defined as decreasing trend in $\mathrm{SPO}_{2}$ less than $88 \%$ and was treated with increasing flow rate of Oxygen and respiratory support as needed. Hypotension was defined as a fall in SBP of more than $20 \%$ from the baseline, or SBP less than $90 \mathrm{~mm} \mathrm{Hg}$ and was treated with increased rate 
of Ringer's Lactate infusion and intravenous Ephedrine or Phenylephrine, as appropriate, in increments. Bradycardia ( $\mathrm{HR}<50 / \mathrm{min}$ ) was treated with Atropine 0.5 mg. Tachycardia (HR > 100/min) and hypertension (SBP $>30 \%$ increase from baseline) were treated with betablocker only after addressing the patients' discomfort, anxiety and pain.

Time of occurrence, management and outcome of all the events including anxiety, right shoulder pain, headache, nausea, vomiting and shivering were recorded. Anxiety was treated with Midazolam and pain with Fentanyl. Total intra-operative fluid infused, operative blood loss, and need for Midazolam, Fentanyl, general anaesthesia, vasopressors, Atropine, beta-blocker, anti-emetics, and any other medication were recorded.

Criteria for conversion of anaesthesia to GA included: surgeon's decision to convert surgery to open cholecystectomy, patient's demand for GA, anxiety not relieved with Midazolam up to two $\mathrm{mg}$, pain not relieved by Fentanyl up to two microgram $/ \mathrm{kg}$, patient discomfort in inserting nasogastric tube, and organ damage or an alarming surgical bleeding.

Patients were shifted to the post-anaesthesia care unit after surgery and maintained on intravenous fluids for fourhours. Analgesics included intravenous Paracetamol one gram every eight hour regularly; and, Tramadol and Fentanyl sequentially only when needed. At six, 12 and 24 hours pain (Verbal Analogue Score, with ' 0 ' the nil and ' 10 ' the maximal imaginable) and cognitive function of patients were assessed. Other post-operative events including discomfort, nausea, vomiting, shoulder pain, urinary retention, headache, or any neu rologic complaint were also recorded. Patients were routinely discharged home the next day if no complications occurred. They were followed for noting any complications and days of hospital stay after surgery were recorded.

Microsoft Excel 2016 was used for data tabulation. Quantitative variables were expressed as mean (standard deviation) and range. Qualitative variables were expressed as frequencies and percentages. Univariate analysis for peri-operative events and bivariate analysis between the outcome and explanatory variables were performed.

\section{RESULTS}

A total of 82 patients were assessed for eligibility. Of these, 12 patients did not meet inclusion criteria, whereas, seven patients did not provide consent. Operating surgeon's unwillingness was the reason for exclusion in nine patients.

The mean age of patients undergoing surgery was 71.4 years and ranged from 65 to 78 years. The height ranged from 150 to $176 \mathrm{~cm}$ with the mean of $159.7( \pm 7.42) \mathrm{cm}$. The mean body weight of patients was $59.22( \pm 16.66) \mathrm{kg}$ at a range of 52 to $79 \mathrm{~kg}$. Co-morbidities were observed in 40 patients (Table 1). Other patient characteristics are illustrated in Table 1.

\section{Table 1: Patient profile $(\mathbf{n}=\mathbf{5 4})$}

\begin{tabular}{lc|}
\hline Parameters & $\begin{array}{c}\text { Number (\%) of } \\
\text { patients }\end{array}$ \\
\hline ASA physical status I: II: III & $14: 32: 8$ \\
\hline Male: Female ratio & $21: 33$ \\
\hline Presence of medical co-morbidity & $40(78.43)$ \\
\hline Hypertension & $21(41.17)$ \\
\hline COPD/Asthma & $10(19.60)$ \\
\hline Left ventricular diastolic & $6(11.76)$ \\
dysfunction & $4(7.84)$ \\
\hline Diabetes mellitus & $2(3.92)$ \\
\hline Ischemic heart disease & $2(3.92)$ \\
\hline Arrhythmias & $2(3.92)$ \\
\hline Hypothyroidism &
\end{tabular}

Numbers may not add up as same patient might have more than one co-morbidity

COPD:Chronic obstructive pulmonary disease

ASA:American Society of Anesthesiologists

SA was performed without difficulty in 54 patients. There wasno block failure and sensory block level was achieved from minimum of T 5 to maximum of T 2 (median of T 4). Surgery was converted to open cholecystectomy in three patients; one due to complicated gall stone disease and two patients in whom IAP could not be maintained due to technical difficulties with the $\mathrm{CO}_{2}$ insufflator. Further analysis included 51 patients who tolerated surgery well and did not need anaesthetic conversion to GA.

Intra-operatively, nine patients complained of right shoulder tip pain and six received Fentanyl for relief (Table 2). None of the patients had serious cardiopulmonary problems, except for transient hypotension and bradycardia (Table 2). SBP normalized with rapid increment of fluid infusion in two patients. Single dose of vasopressor was sufficient in four patients, whereas, nine patients needed two such doses. Other events occurring during intra-operative period are shown in Table 2. 
Table 2: Intra-operative events, complications and medications

\begin{tabular}{lc}
\hline Event & Number (\%) of patients \\
\hline Right shoulder tip pain & $9(17.64)$ \\
\hline Need for Fentanyl & $6(11.76)$ \\
\hline Need for Midazolam & $8(15.68)$ \\
\hline Hypotension & $15(29.41)$ \\
\hline Shivering & $4(7.84)$ \\
\hline Bradycardia & $2(3.92)$ \\
\hline Abdominal discomfort & $2(3.92)$ \\
Nausea & $1(1.96)$ \\
\hline
\end{tabular}

Operating surgeons demanded for inserting nasogastric tube in five patients but was needed in none, after optimizing table tilts and increment of IAP to $10 \mathrm{mmHg}$ in three patients and up to $12 \mathrm{mmHg}$ in two patients. No surgical complications were observed and there was no need for fourth trocar for surgery. Surgical findings, modifications, and needs are illustrated in Table 3.

\section{Table 3: Surgical findings}

\begin{tabular}{lc}
\hline Parameter & Value \\
\hline $\begin{array}{l}\text { Conversion to open cholecystectomy, } \\
\mathrm{n}(\%)\end{array}$ & $3(5.88)$ \\
\hline $\begin{array}{l}\text { Need for raising IAP, } \mathrm{n}(\%) \\
\text { Duration of pneumoperitoneum, mean } \\
(\mathrm{SD}) \text { min }\end{array}$ & $26.75( \pm .80)$ \\
\hline $\begin{array}{l}\text { Duration of surgery, mean (SD) min } \\
\text { Total fluid infused, mean (SD) ml }\end{array}$ & $39.20( \pm 17.34)$ \\
\hline $\begin{array}{l}\text { Blood loss, mean (SD) ml } \\
\text { Sub-hepatic drain insertion, } \mathrm{n}(\%)\end{array}$ & $42.73( \pm 24.64)$ \\
\hline
\end{tabular}

IAP:intra-abdominal pressure

SD:standard deviation

Table 4 shows post-operative events related to surgery and anaesthesia. No patient complained of headache or other neurologic sequelae related to SA and there was no deterioration in the cognitive function. Twenty four patients recovered at six hours following surgery and were ready to be discharged from hospital. However, all patients were kept in hospital overnight for monitoring and were discharged the following day. There was no mortality observed during the study period.

Table 4: Post-operative events

\begin{tabular}{lc}
\hline Event & Value \\
\hline Nausea/vomiting, $\mathrm{n}(\%)$ & $3(5.88)$ \\
\hline Shoulder pain, $\mathrm{n}(\%)$ & $2(3.92)$ \\
\hline Urinary retention, $\mathrm{n}(\%)$ & $4(7.84)$ \\
\hline Hospital stay, mean (SD), range days & $3.2( \pm 1.6), 1$ to 6 \\
\hline
\end{tabular}

SD:standard deviation
Post-operative pain scores and analgesic requirements are shown in Table 5.

\section{Table 5: Post-operative pain scores and analgesic need in 24 hours}

\begin{tabular}{lc}
\hline Parameter & Value \\
\hline VAS at 6 hours & $4.20( \pm 2.32), 0$ to 8 \\
\hline VAS at 12 hours & $4.22( \pm 2.34), 0$ to 10 \\
VAS at 24 hours & $3.20( \pm 1.90), 0$ to 10 \\
\hline $\begin{array}{l}\text { Analgesic need } \\
\text { Tramadol need: Fentanyl need }\end{array}$ & $5: 0$ \\
\hline
\end{tabular}

Values are mean ( \pm standard deviation) range

VAS:Verbal Analogue Score for post-operative pain

* Number of patients needing analgesics apart from regular intravenous Paracetamol

\section{DISCUSSON}

This study shows that SA is efficient and can be applied safely for conducting $\mathrm{LC}$ in the elderly with potentially decreased physiologic reserves and associated comorbidities. Even though, many surgeons are reluctant to go along with SA. There might be various reasons for this. In our experience, nine eligible and willing patients had to be declined for this reason. For LC, the surgeons' choice until now is GA, supposedly to avoid aspiration and respiratory embarrassment. But the need for GA is being debated as advantageous outcomes with SA are increasingly being reported ${ }^{4-7,10,11}$

In our study, GA was not required for patients in whom surgery completed laparoscopically. Rate of conversion from SA to GA while conducting LC varies widely from nil to $55 \%$ with a median value at $26 \% \%^{7,10-12}$. The most common reason for this conversion is intractable shoulder pain, the incidence of which is around 13 to $47 \%, 7,10-12$. Out of nine patients (18\%) who experienced shoulder pain in our study, reassurance was sufficient for two; whereas, six patients required Fentanyl along with Midazolam. One patient complained of shoulder pain from the start of $\mathrm{CO}_{2}$ insuffflation, but it disappeared immediately after intra-peritoneal Bupivacaine instillation. Low incidence and a reduced intensity of shoulder pain in our patients presumably accounted for lack of need for GA. Most important contributing factor must have been intra-peritoneal Bupivacaine ${ }^{13}$, followed by pre-emptive Paracetamol, low $\mathrm{CO}_{2}$ flow rate, low $\mathrm{IAP}^{14}$, and Dexamethasone.

The rate of conversion from laparoscopic surgery to open cholecystectomy is higher in the elderly ${ }^{15}$. Organ handling and visceral stimulation during open 
cholecystectomy might far exceed the SA-induced sensory block. Thus we set criteria to provide GA whenever surgical plan was changed. This resulted in three patients receiving GA in our study. The finding that the patients whose surgery were completed laparoscopically did not require GA, implies that minimal invasive laparoscopic technique and minimal stress SA match well.

The most common event occurring in our patients was hypotension (29\%). This is a bit higher than that reported by Tzovaras et al but the participants in their study were much younger ${ }^{7}$. The correlation between age and hypotension during SA has been previously reported and is re-emphasized by our finding ${ }^{16}$. It ranges from 25 to $82 \%$ in the elderly ${ }^{17,18}$. With the combination of fluids and vasopressors given early at a lower threshold criteria, hypotension was easily controlled and none of our patients suffered myocardial or renal consequences.

Hypertension was the most common morbidity in our patients. Neurohumoral response during laparoscopic surgeries can increase systemic vascular resistance, HR and myocardial oxygen consumption ${ }^{19,20}$. Interaction among effects of exogenous $\mathrm{CO}_{2}$, raised IAP and reverse Trendelenburg position during $\mathrm{LC}$ can thus precipitate myocardial ischemia and dysrhythmias ${ }^{21-23}$. LC still remains the therapy of choice even in the sick elderly in order to prevent serious complications of cholelithiasis, but at the cost of a higher rate of morbidities under $\mathrm{GA}^{15,24,25}$. Notably, noneof ourpatientsrequired treatment for hypertension and tachycardia. Similarly, adequate pre-operative optimization of ischemic heart disease and early mild diastolic dysfunction in our hypertensive patients did not pose untoward effects peri-operatively. Since cardiovascular effects of $\mathrm{CO}_{2}$ pneumoperitoneum have not been studied under the setting of $S A$ and in the elderly, we can only deduce that SA-induced reduction in stress response and afterload could balance the effects mediated by pneumoperitoneum. This might also explain why none of our patients developed new arrhythmias or ischemia. Dysrhythmias can also be precipitated by rapid $\mathrm{CO}_{2}$ insufflation rates due to peritoneal stretching ${ }^{26}$. Therefore, a low insufflation rate of one litre/minute was used in our study. In addition, the possible effects of pneumoperitoneum could have been partially offset by our use of a low IAP14.

In five of our patients, however, eight mmHg IAP proved to be inadequate for optimal surgical exposure. It was increased sequentially to a maximum of $12 \mathrm{mmHg}$ till the cystic duct/artery were safely clipped and then was decreased to eight $\mathrm{mmHg}$. This method helped us to avoid inserting nasogastric tube and its associated discomforts. There was minimal blood loss and rate of placement of sub-hepatic drains was small (6\%). Mean operative time of 39 minutes and no need for creation of the fourth trocar might reflect that there was not much difficulty for the surgeons.

The second most common co-morbidity in our study population was chronic obstructive pulmonary disease (COPD). A similar finding is reported by other studies ${ }^{15,24}$. GA, pneumoperitoneum and upper abdominal surgery impact negatively on pulmonary function. Advanced age also predisposes to post-operative pulmonary complications ${ }^{27}$. Positive pressure ventilation and pneumoperitoneum can result in ventilation-perfusion mismatch and alveolar injury. Higher IAP reduces thoracic compliance and may result in pneumothorax and pneumomediastinum in COPD patients receiving mechanical ventilation ${ }^{28}$. In our patients SA provided adequate anaesthesia without the need for airway instrumentation and mechanical ventilation, which must have contributed for the absence of pulmonary complications. Concerns still remain regarding inadequate ventilation due to SA-induced intercostal muscle paralysis, especially in respiratory-compromised patients. However, our COPD patients did not show oxygen desaturation or respiratory acidosis. It might reflect that during short laparoscopic procedures and, when applied IAP is low, the $\mathrm{CO}_{2}$ uptake might be minimal. And, physiologic compensation with enhanced respiratory drive is usually sufficient to eliminate $\mathrm{CO}_{2}{ }^{29}$.

The most important advantage of SA in the elderly high-risk patients may be the associated reduction in morbidity rates 8 . This is shown by the absence of major cardio-pulmonary complications, and a mean hospital stay of 3.2 days in our study, which is less than the report of elderly patients undergoing LC under $\mathrm{GA}^{24}$. Post-operative pain in our patients was well controlled with regular Paracetamol without requiring opioids. This correlates with a recent meta-analysis concluding less post-operative pain after LC performed under $\mathrm{SA}$ as compared to $\mathrm{GA}^{12}$. Minimal occurrence of post-operative nausea and vomiting is in accordance with those of previous findings ${ }^{4,7,11}$. All of our patients remained awake and oriented at the end of surgery. Avoidance of GA and opioids must have contributed for the lack of deterioration in cognitive function. There was no post-operative sore throat, aspiration, headache or neurological complaint. Need for urinary catheterization was observed in $8 \%$ patients in our study. It did not affect the recovery of the patients and is quite similar to a previous study ${ }^{\top}$. And also urinary retention is known to 
be related to SA with rates of up to $20 \%$ in some series ${ }^{30}$.

Only from our findings it is quite difficult to determine whether the surgeons and the patients were satisfied with the employed anaesthetic technique. Given the increasing importance of use of SA for LC in clinical practice, this may represent a significant limitation. And a further randomized, controlled trial comparing SA with GA to evaluate patients' satisfaction, surgeons' difficulty and cost-effectiveness may be warranted.

The human body has the capability to compensate for the age-related changes to some extent. But elderly, healthy or sick, have a limited physiologic reserve that can become evident during the periods of stress. In these patients we should be particularly aware of tailoring the care to the individual patient's needs and make a surgical plan based on a joint decision between care providers and the patient.

To the author's best knowledge, this is the first study to assess safety and applicability of SA for conducting LC in the elderly. Advantages of SA are highly desirable in

\section{REFERENAES}

1. Sandor J, Sandor A, Zaborszky A, Megyaszai S, Benedek G, Szeberin Z. Why laparoscopic cholecystectomy today? Surg Today. 1996;26(7):556-60.

2. Silbert B, Evered L, Scott DA. Cognitive decline in the elderly: is anaesthesia implicated? Best Pract Res Clin Anaesthesiol. 2011 Sep;25(3):379-93.

3. McDaniel M, Brudney C. Postoperative delirium: etiology and management. Curr Opin Crit Care. 2012 Aug;18(4):372-6.

4. Hamad MA, El-Khattary OA. Laparoscopic cholecystectomy under spinal anesthesia with nitrous oxide pneumoperitoneum: a feasibility study. Surg Endosc. 2003 Sep;17(9):1426-8.

5. vanZundert AA, Stultiens G, Jakimowicz JJ, van den Borne BE, van derHam WG, Wildsmith JA. Segmental spinal anaesthesia for cholecystectomy in a patient with severe lung disease. $\mathrm{Br} J$ Anaesth. 2006 Apr;96(4):464-6.

6. vanZundert $A A$, Stultiens $G$, J akimowicz JJ, Peek D, van der Ham WG, Korsten HH, et al. Laparoscopic cholecystectomy under segmental thoracic spinal anaesthesia: a feasibility study. $\mathrm{Br} J$ Anaesth. 2007;98(5):682-6.

7. Tzovaras G, Fafoulakis F, Pratsas K, Georgopoulou S, Stamatiou G, Hatzitheofilou C. Spinal vs general elderly where co-morbidities often make peri-operative course hazardous and difficult. We must attempt our best to protect these patients from the disadvantages of GA. It is emphasized that we are now in a position to offer anaesthetic choices for the elderly co-morbid patients appearing for LC. And we recommend to start with SA for LC, as we can convert the technique anytime if needed. Nonetheless, it is not wise to persist with the technique would the surgery be excessively prolonged or the patients suffer discomfort of any sort.

\section{CONAUSON}

Spinal anaesthesia in the elderly is efficient and safe to conduct laparoscopic cholecystectomy for treating uncomplicated cholelithiasis with minimal modifications in surgical technique.

\section{ACANOMFDGEMEN}

Author is indebted to MD Anaesthesia residents and nurses from post-anaesthesia care unit of Kathmandu Medical College, and a number of people without whose encouragement and assistance this study would not have been completed.

anesthesia for laparoscopic cholecystectomy: interim analysis of a controlled randomized trial. Arch Surg. 2008 May;143(5):497-501.

8. Rodgers A, Walker N, Schug S, McKee A, Kehlet H, van Zundert $A$, et al. Reduction of postoperative mortality and morbidity with epidural or spinal anaesthesia: results from overview of randomized trials. BMJ. 2000 Dec; 321(7275):1493-1505.

9. World Medical Association Declaration of Helsinki: ethical principles for medical research involving human subjects. JAMA. 2013 Nov;310(20):2191-4.

10. Ellakany M. Comparative study between general and thoracic spinal anesthesia for laparoscopic cholecystectomy. Egyptian J Anaesth. 2013 Oct;29(4):375-81.

11. Imbelloni LE, Fornasari M, Fialho JC, Sant'Anna $R$, Cordeiro JA. General anesthesia versus spinal anesthesia for laparoscopic cholecystectomy. Rev Bras Anestesiol. 2010 May-J un; 60(3):217-27.

12. Yu G, Wen Q, Qiu L, Bo L, Yu J. Laparoscopic cholecystectomy under spinal anaesthesia vs. general anaesthesia: a meta-analysis of randomized controlled trials. BMC Anesthesiol. 2015; 15:176.

13. Boddy AP, Mehta $S$, Rhodes $M$. The effect of intraperitoneal local anesthesia in laparoscopic cholecystectomy: a systematic review and metaanalysis. Anesth Analg. 2006 Sep; 103(3):682-8. 
14. Gurusamy KS, Samraj K, Davidson BR. Low pressure versus standard pressure pneumoperitoneum in laparoscopic cholecystectomy. Cochrane Database Syst Rev. 2009 Apr 15; (2):CD006930.

15. Pessaux P, Tuech JJ, Derouet N, Rouge C, Regenet N, Arnaud JP. Laparoscopic cholecystectomy in the elderly: A prospective study. Surg Endosc 2000;14:1067-9.

16. Carpenter RL, Caplan RA, Brown DL, Stephenson C, Wu R. Incidence and risk factors for side effects of spinal anesthesia. Anesthesiol. 1992 J un;76(6):90616.

17. Moore DC, Bridenbough LD. Spinal (subarachnoid) block. A review of 11574 cases. JAMA. 1966 Mar;195(11):907-12.

18. Critchley LA. Hypotension, subarachnoid block and the elderly patient. Anaesthesia. 1996 Dec; 51(12):1139-43.

19. Odeberg $S$, Ljungqvist $O$, Svenberg $T$, Gannedahl $P$, Backdahl M, von Rosen A, et al. Haemodynamic effects of pneumoperitoneum and the influence of posture during anaesthesiafor laparoscopicsurgery. Acta Anaesthesiol Scand. 1994 Apr;38(3):276-83.

20. Joris JL, Noirot DP, Legrand MJ, Jacquet NJ, Lamy ML. Hemodynamic changes during laparoscopic cholecystectomy. Anesth Analg. 1993 May;76(5):1067-71.

21. Dorsay DA, Greene FL, Baysinger CL. Hemodynamic changes during laparoscopic cholecystectomy monitored with transesophageal echocardiography. Surg Endosc. 1995; 9:128-34.

22. Williams MD, Murr PC. Laparoscopic insufflations of abdomen depresses cardiopulmonary function. Surg Endosc. 1993 Jan-Feb; 7(1):12-6.
23. Bickel A, Marinovski $M$, Shturman $A$, Roguin N, Waksman I, Eitan A. Filtered signal-averaged P-wave duration during Pneumoperitoneum in patients undergoing laparoscopic cholecystectomy: a reflection of pathophysiological cardiac changes. Surg Endosc. 2008 Jan; 22(1):221-7.

24. Annamaneni RK, Moraitis D, Cayten CG. Laparoscopic cholecystectomy in the elderly. JSLS. 2005 Oct-Dec;9(4):408-10.

25. Bingener], RichardsML, SchwesingerWH, Strodel WE, Sirinek KR. Laparoscopic cholecystectomy for elderly patients: gold standard for golden years? Arch Surg. 2003 May; 138(5):531-5.

26. Reed DN Jr, Duff JL. Persistent occurrence of bradycardia during laparoscopic cholecystectomies in low-risk patients. Dig Surg. 2000;17(5):513-7.

27. Hall JC, Tarala RA, HallJ L, Mander J. A multivariate analysis of the risk of pulmonary complications after laparotomy. Chest. 1991;99(4):923-7.

28. Rauh R, Hemmerling TM, Rist M, Jacobi KE. Influence of pneumoperitoneum and patient positioning on respiratory system compliance. J Clin Anesth. 2001 Aug; 13(5): 361-5.

29. Nishio I, Noguchi J, Konishi M, Ochiai R, Takeda J, Fukushima K. The effects of anesthetic techniques and insufflating gases on ventilation during laparoscopy. Mausi. 1993 Jun; 42(6):8626.

30. Jensen $P$, Mikkelsen $T$, Kehlet $H$. Postherniorrhaphy urinary retention - effect of local, regional, and general anesthesia: A review. Reg Anesth Pain Med. 2002 Nov; 27(6):612-7. 